\title{
OASI Care Bundle
}

Mandie Scamell ${ }^{1}$, James Thornton ${ }^{2}$, Katherine Hales $^{3}$, Mary Renfrew ${ }^{4}$, Hannah Dahlen ${ }^{5}$, Margaret Jowitt ${ }^{6}$, Soo Downe ${ }^{7}$, Lindsay Gillman ${ }^{8}$, Octavia Wiseman ${ }^{9}$, Jane Forman ${ }^{8}$, Nicky Grace ${ }^{3}$, Deborah Davis ${ }^{10}$, Anna-Marie Madeley ${ }^{11}$, Debbie Chippington ${ }^{12}$, Lorna Lawther $^{13}$, and Ethel Burns ${ }^{14}$

${ }^{1}$ City University

${ }^{2}$ Nottingham City Hospital

${ }^{3}$ Association of Radical Midwives

${ }^{4}$ University of Dundee

${ }^{5}$ Western Sydney University

${ }^{6}$ self employed

${ }^{7}$ University of Central Lancashire

${ }^{8}$ Kingston University

${ }^{9}$ City, University of London

${ }^{10}$ University of Canberra and ACT Government Health Directorate

${ }^{11}$ University of Bedfordshire Faculty of Health and Social Sciences

${ }^{12}$ Association for Improvements in Maternity Services

${ }^{13}$ Queen's University Belfast Faculty of Medicine Health and Life Sciences

${ }^{14}$ Oxford Brookes University

July 20, 2021

Sir,

We welcome Gurol-Urganci I and Bidwell et al's evaluation of the impact of the care bundle to reduce obstetric anal sphincter injury (OASI) published in your August edition last year.[1] The article reports much needed evidence on the efficacy of an intervention that has already taken hold in many maternity services across the country.

Despite the article's timely nature, we would like to voice our disappointment in the quality of the evidence of support for the care bundle Meulen and Thakar et al provide, and the recommendations made. The article fails to consider important evidence in this area of maternity care prompting this response. In particular, the authors miss the opportunity to contextualise the relatively low-level evidence they take from five articles - reporting three Scandinavian cohort studies and one educational intervention study on manual assistance during the final part of the second stage of labour (including gripping the baby's chin through the perineum) - with the compelling findings from the Cochrane review on Perineal techniques during the second stage of labour for reducing perineal trauma. [2] This omission is important because the Cochrane review indicates that warm compresses have a bigger positive effect on OASI than the OASI care bundle reported by Meulen and Thakar et al's. Furthermore, the Cochrane review provides evidence suggesting that hands off the perineum may protect women from episiotomy; an outcome which Meulen and Thakar et al acknowledge remained unchanged despite the third component in the care bundle aiming to 'use of episiotomy when clinically indicated'. The selective nature of the evidence quoted, undermines the credibility of inferences that can be made from the findings. We suggest therefore, that caution should be taken when reading the 
authors conclusions.

Our second concern rests upon the authors failure to account for the surprisingly small positive effect of the care bundle compared with the Scandinavian studies they quote. Meulen and Thakar et al report a $0.3 \%$ decrease in OASI compared with a $3.6 \%$ reduction; [3]

$3 \%$ reduction; [4] a $2.6 \%$ reduction for low risk women; [5] and a $2.1 \%$ reduction in the various observational studies [6] Such a small effect in an open trial could easily be caused by ascertainment bias. Again, the quality of the previous Scandinavian studies make interpretation difficult but the marked difference in results between Scandinavia and England suggests caution should be taken when reading the authors conclusions.

Our final concern pertains to women's experience of the care bundle. Not only is the acceptability of the intervention not considered in this evaluation - a significant oversight given the conspicuous lack of evidence on this - there are ethical issues within the evaluation that deserve attention. The intervention description in figure 1 claims that women were informed about what could be done to reduce OASI. This does not appear to be entirely true given the lack of consideration of warm compresses and hands off to protect against episiotomy. Even more unsettling is the statement 'MPP should be used unless the woman objects', implying little consideration for autonomy and informed consent.

For the above reasons, we are not only disappointed with the BJOG article but with the professional stakeholder investment in the intervention which seems to have been widely and uncritically supported, with some support even being somewhat evangelical, despite the limited evidence for support.

Signatures,

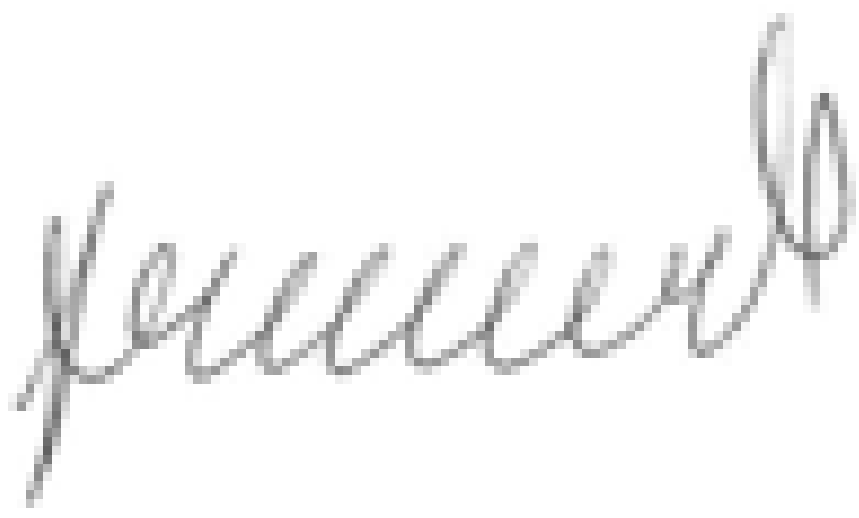

Dr Mandie Scamell, City University of London 


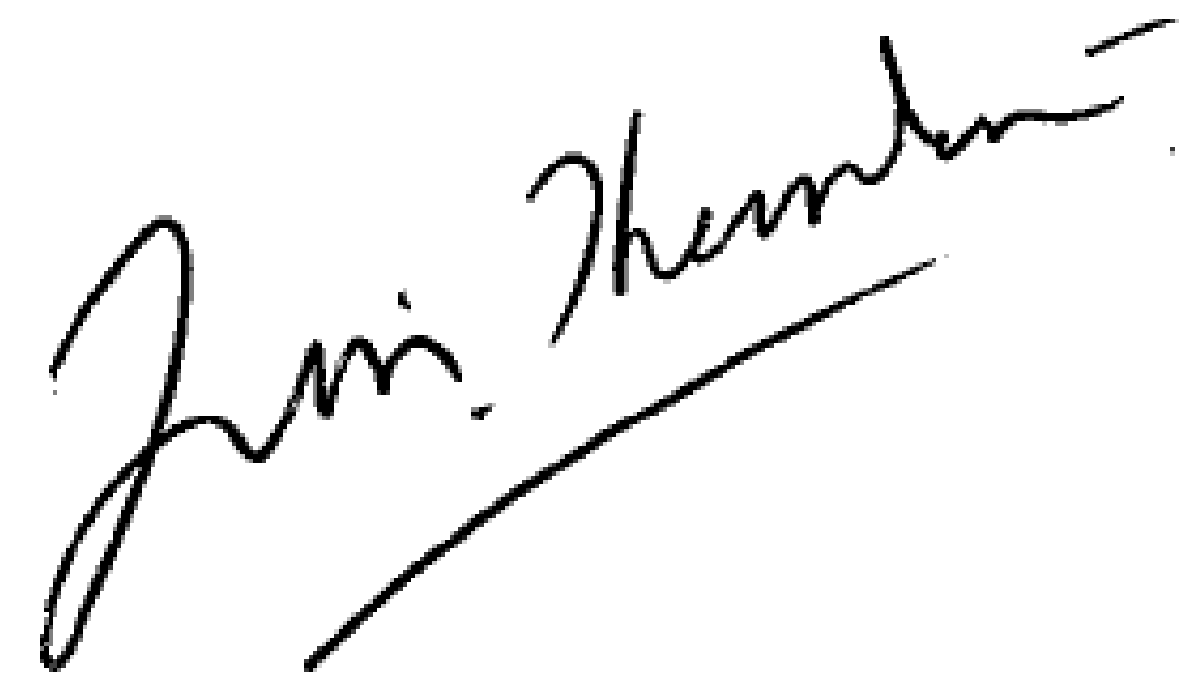

Jim Thornton, University of Nottingham.

Katherine Hales, Association of Radical Midwives

Prof Mary Renfew, School of Health Sciences, University of Dundee

Prof Hannah Dahlen, Western Sydney University

Margret Jowit, Association of Radical Midwives

Prof Soo Downe, University Central Lancashire

Associate Prof Lindsay Gillman, Kingston University

Nicky Grace, Association of Radical Midwives

Octavia Wiseman, Lewisham \& Greenwich NHS Trust

Jane Forman, Kingston University

Nicky Grace, Association of Radical Midwives

Prof Deborah Davis, ACT Government Health Directorate and University of Canberra

Anna-Marie Madeley, University of Bedfordshire

Debbie Chippington, Association for Improvements in the Maternity Services

Dr Lorna Lawther, Queens University Belfast

Dr Ethel Burns, Oxford Brookes University

1 Gurol-Urganci I, Bidwell P, Sevdalis N, et al. Impact of a quality improvement project to reduce the rate of obstetric anal sphincter injury: a multicentre study with a stepped-wedge design.BJOG An Int J Obstet Gynaecol 2020;:1471-0528.16396. doi:10.1111/1471-0528.16396

2 Aasheim V, Nilsen ABV, Reinar LM, et al. Perineal techniques during the second stage of labour for reducing perineal trauma. Cochrane Database Syst. Rev. 2017;2017 . doi:10.1002/14651858.CD006672.pub3

3 Rasmussen OB, Yding A, Anh $\varnothing \mathrm{J}$, et al. Reducing the incidence of Obstetric Sphincter Injuries using a hands-on technique: an interventional quality improvement project. BMJ Qual Improv Reports 2016;5 :u217936.w7106. doi:10.1136/bmjquality.u217936.w7106 
4 Hals E, Øian P, Pirhonen T, et al. A Multicenter Interventional Program to Reduce the Incidence of Anal Sphincter Tears. Obstet Gynecol 2010;116 :901-8. doi:10.1097/AOG.0b013e3181eda77a

5 Stedenfeldt M, Øian P, Gissler M, et al. Risk factors for obstetric anal sphincter injury after a successful multicentre interventional programme. BJOG An Int J Obstet Gynaecol2014;121 :83-91. doi:10.1111/14710528.12274

6 Laine K, Skjeldestad FE, Sandvik L, et al. Incidence of obstetric anal sphincter injuries after training to protect the perineum: Cohort study. BMJ Open 2012;2 :1649. doi:10.1136/bmjopen-2012-001649 